\title{
THE CREATION OF VEHICLE WASTE MANAGEMENT SYSTEM IN MOSCOW
}

\author{
Nadejda Boyarchuk \\ Moscow State Committee on Environmental Protection, Russia
}

Introduction. Moscow City is one of the greatest megapolises of the world and the largest transport system in Europe relating to scales of its development, amount of exploited transport vehicles. volumes of passenger and freight traffics.

Autotransport has become the most powerful source of negative influence on environment in Moscow recently. The significant increase in number of cars is the main reason of such situation taking into account share of old transport in the total number of vehicles, slow development of transport infrastructure, not always satisfactory level of cars technical condition. The problem of environmental pollution by motor transport is manifested not only in influence of functioning transporte, but also in negative influence of end-of-life cars.

At present, some enterprises and organizations of Moscow region make proposals on developments for improvement of the existing system of collection and treatment of vehicles.

Making conception provides creation of a regional system for abandoned and end-of-life vehicles. The technological scheme consists of stages of collection, preliminary preparation, metallurgy or shredding treatment and metal/metalloid scrap sorting. The Conception includes the main technico-econmical indicators of the proposed system of processing.

Making the complexes of conversion of vehicle waste is a large investment project, requiring not only attraction of significant funds, but also creation of a centralaized system, allowing guarantee the arrival of waste flow.

The aim of the project is to develop organizational, financial, legal mechanisms and technical measures for making a motivated system. It must be based on the Polluter Pays Principle and consequent conversion of cars wracks into commercial goods. This work includes also a forecast for transport waste volumes. Without these data it is impossible to make planning for development of the system.

Present situation. There are more than 2,0 mln. cars, including 1,8 mln.passengers cars, which are registered by the Moscow Road State Inspection. $0,2 \mathrm{mln}$. passenger cars belong to juridical persons, rest - to natural persons. The one third of the city cars fleet is presented by vehicles older than 7 years. Annualy up to 150 thous. transport vehicles are being registered. In addition, up to $0,8 \mathrm{mln}$. cars registered in other regions of Russia are used in Moscow. 
The Number of transport vehicles in Moscow registered by The Moscow State Road Inspection

\begin{tabular}{|l|l|l|l|l|l|l|l|l|}
\hline Year & 1992 & 1993 & 1994 & 1995 & 1996 & 1997 & 1998 & 1999 \\
\hline $\begin{array}{l}\text { Number , } \\
\text { thous. units }\end{array}$ & 1062 & 1119,5 & 1301,1 & 1549,2 & 729,4 & 888,4 & 2017,6 & 2124,6 \\
\hline
\end{tabular}

Dynamics of the total increase and number of vehicle fleet

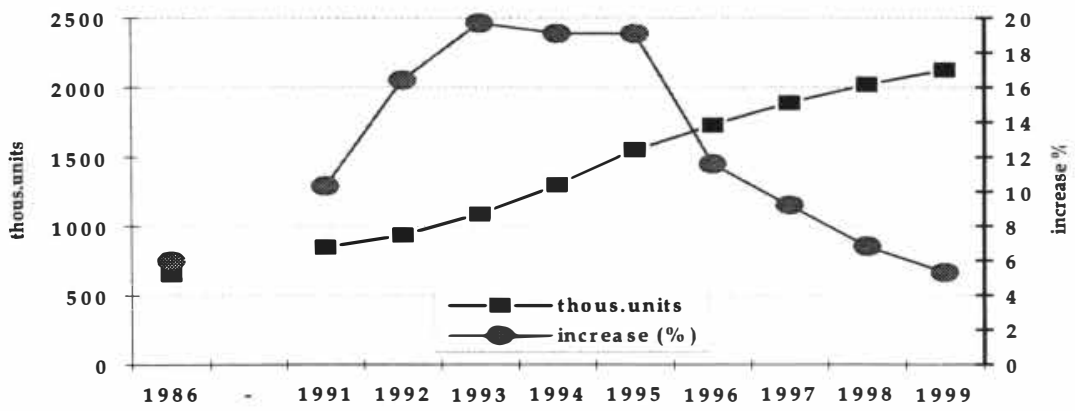

The dominant group in the structure of transport vehicles is presented by passenger cars $(81 \%)$, the share of trucks and buses accounts for $17 \%$, other types of transport - about $2 \%$.

\section{Car fleet structure in Moscow}

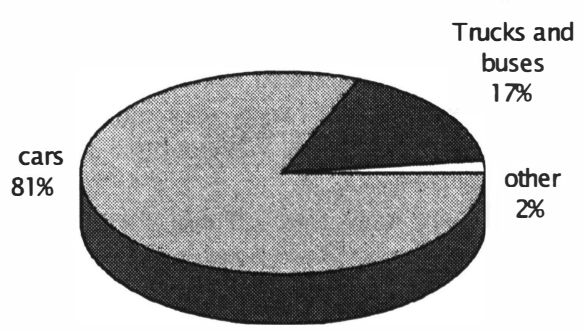

Property cathegories. In the last years the number of the transport fleet in Moscow has been continuously increasing and amounted to 2124,6 thous.units on Jan.1,1999. This increase of the fleet is attributed to private passenger cars basically.

Reduction of amount of transport of juridical persons in the structure of Moscow car fleet 
in the last years is explained by the stable trend of reduction of cars fleet of municipal companies "Mosgortans", "Mosautotrans", "Mosautolegtrans ". The reasons of crisis condition of municipal transport companies are conditioned by the total economic crisis in Russia.

The share of the private cars accounts for $86,4 \%$ or more than 1,8 mln.units. The fleet of transport vehicles of juridical persons accounts for $13,6 \%$ or 270 thous. units.

The diagrams graphically show the existing trend of reduction of specific share of transport of juridical persons under stable increase in number of the natural owners.

\section{Change in Moscow transport fleet structure as to forms of juridical persons}

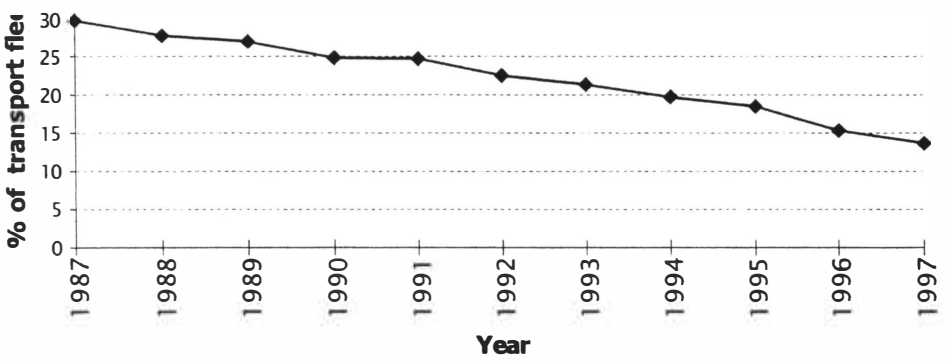

\section{Change in Moscow transport fleet structure as to forms of natural persons}

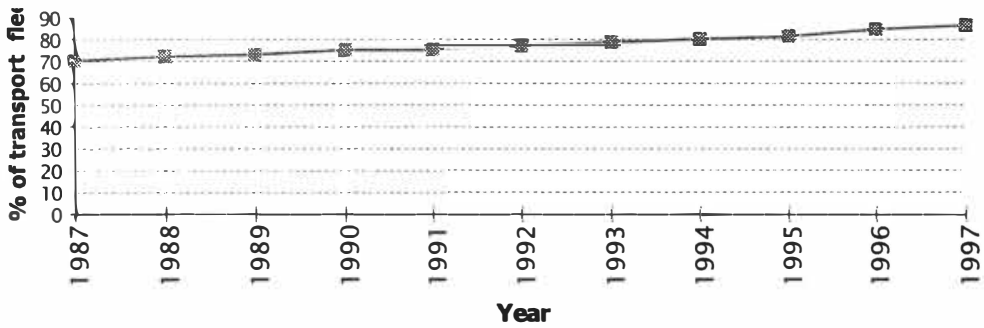

Age factors of the transport vehicles fleet. According to statistics of the State Road Inspection increase in number of cars has reached in the last years about a few hundred thousand secars a year and may be attributed basically to import second-hand foreign cars. Average life of passenger car is about $10-15$ years. On foreign data average life of car in Europe is 14 years.

The practice of transport inspection shows that $77 \%$ cars, which are used more than 9 years, suffer different technical faults. Thereby, 9-10 years period of usage of car is considered 


\section{ECOLOGICAL TECHNOLOGY AND MANAGEMENT}

KALMAR, SWEDEN, September 22-24, 1999

as a critical term. Starting from this term it is possible to attribute such cars to a group of potentially useless from the technical point view. Considering that at present average service life of transport vehicles is 13-15 years, there are more than 120-130 thousand of units of cars become the subjects to salvaging annually.

The structure of transport fleet (including trailors) in Moscow as to age groups.

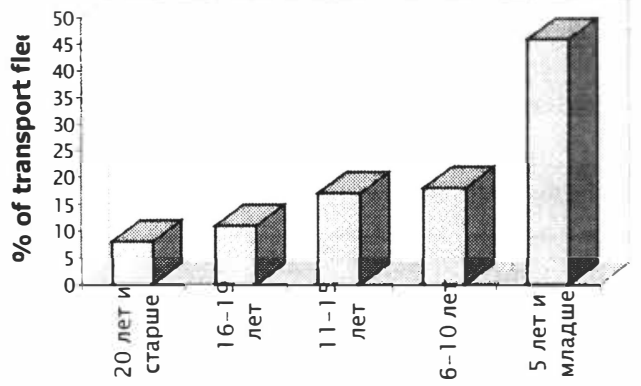

The share of exploited cars in Moscow, which age is older than 9 years, accounts for $46 \%$ of the total vehicle fleet (or 1237 thous. units). The sharp increase of car fleet in 90 -s will result in an increase in volumes of waste in the near future.

Estimate and prognosis for transport waste volumes in Moscow. Transport vehicles wastes include : units, equipment, parts of cars, worn-out tyres, forfeited their own consumer characteristics in the process of usages.

The potential sources of generating of transport waste are:

- transport vehicles written off from balances of municipal, state and private organizations and enterprises:

- transport vehicles of natural owners, sorted out and deregistrated by The State Road Technical Inspection from technical point view;

- transport vehicles not subjecting to reconstruction or/and abandoned by owner as a result of road accident.

The group of written off municipal transport is the most controlled one, but in ditto time it is one of the the most poor sources of waste.

More greater problem is the estimation and checking the flow of old vehicles registered on juridical person, but residing in private property ( the

different commercial structures, enterprises, organizations). If in the forthcoming years existing factors remain unchangeable (the volume of collection - $20 \%$ and volume of conversion - $8 \%$ from volumes of genrationtion), it will be possible to forecast the increase in an unprocessed waste volume. It is possible to forecast the growing flow of generated waste volumes in next few years, which will amount to 80-90 thousand units per year for passenger motor vehicles fleet in Moscow. 
ECOLOGICAL TECHNOLOGY AND MANAGEMENT

KALMAR, SWEDEN, September 22-24, 1999

Number of old and dismantled vehicles

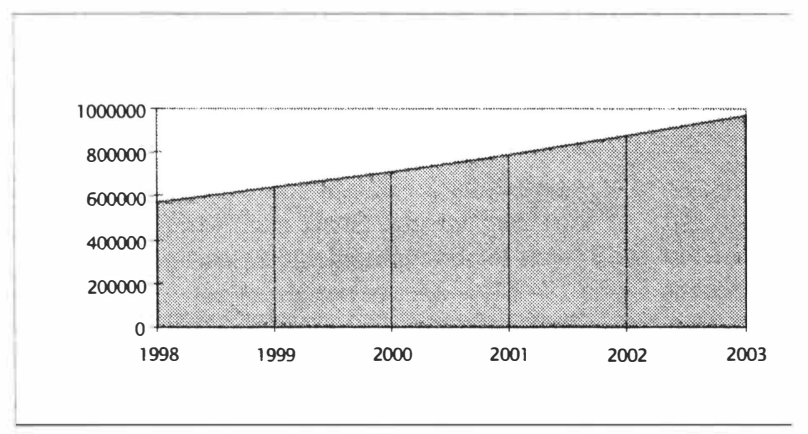

Number of worn-out tyres - 87000 tons/year

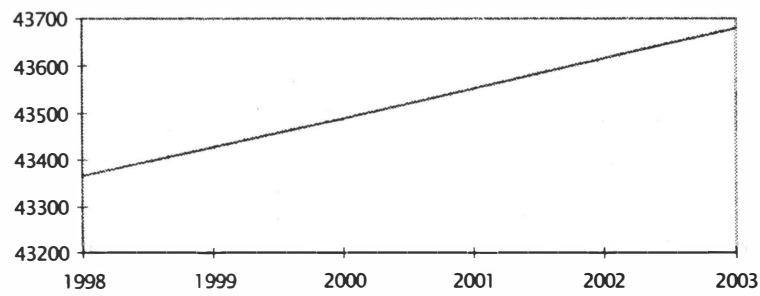

Number of worn-out batteries - 16600 tons/year.

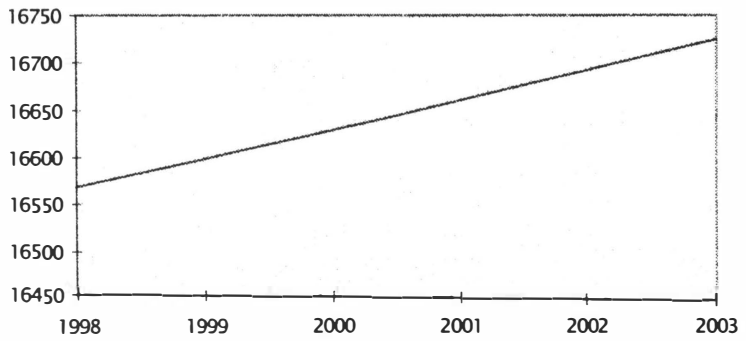


Environmental aspect. In the last years the number of cars on the city roads has increased. Under conditions of absence of strict normative-legal acts transport vehicles are being left by owners on streets, in uptowns, ravines, on abandoned lots of the town territory. Assuming that even if 1 litre of petroleum products or other harmful liquids from each abandoned vehicle enters into the soil no less than 20 tons of harmful substances will penetrate into the soil in Moscow annualy.

Car is a good source of row materials for re-use and recycling. On an average a weight of metals accounts for $77 \%$ of total car weight. Sheet steel forms about $50 \%$ from their total amount. Metals account for $95 \%$ of total weight, including also aluminum, copper and zinc, can be used after treatment. Up to $10-14 \%$ of total weight of car are plastics which are used to reduce car weight, to icrease resistance to corrosions and to cut expenditure.

According to western car manufacturers the volume of plastics used in cars is steadly growing and can increase from $12 \%$ in the period $1980-90$ to planned $20-25 \%$ for the year 2000. In Evropean countries recycling of plastic batteries boxes and some plastic parts of bumpers is broadly used.

Currently, there is a stable demand for scrap of ferrous and non-ferrous metals, tyres and used batteries on the market of row materials.

Moscow vehicle waste management system. The existing organizational scheme has 3 levels: strategic, management and technical. This present system is oriented only on collection and utilization the abandoned and dismantled cars; there is no Coordinator in the organizational structure.

The Order of evacuation and utilization of unfit-to-use vehicles, interfering street traffic, and mechanized street cleaning is executed in accordance with Decrees of Mayor of 28.12.1994 №645-PM "Evacuation of abandoned and dismantled vehicles on the territory of Moscow" and of 03.11.1997 №858-PM " Terms and measures on improvement of the system of collection, processing and salvaging of abandoned end dismantled vehicles".

At present abandoned and dismantled vehicles are being indentified by district surveyors of Police, Manager of united customer, Administrative-technical inspections. After that vehicles are evacuated to the special parking lots (keeping places), which are under supervision of prefectures. 
The organizational structure of management of abandoned and dismantled vehicles in Moscow

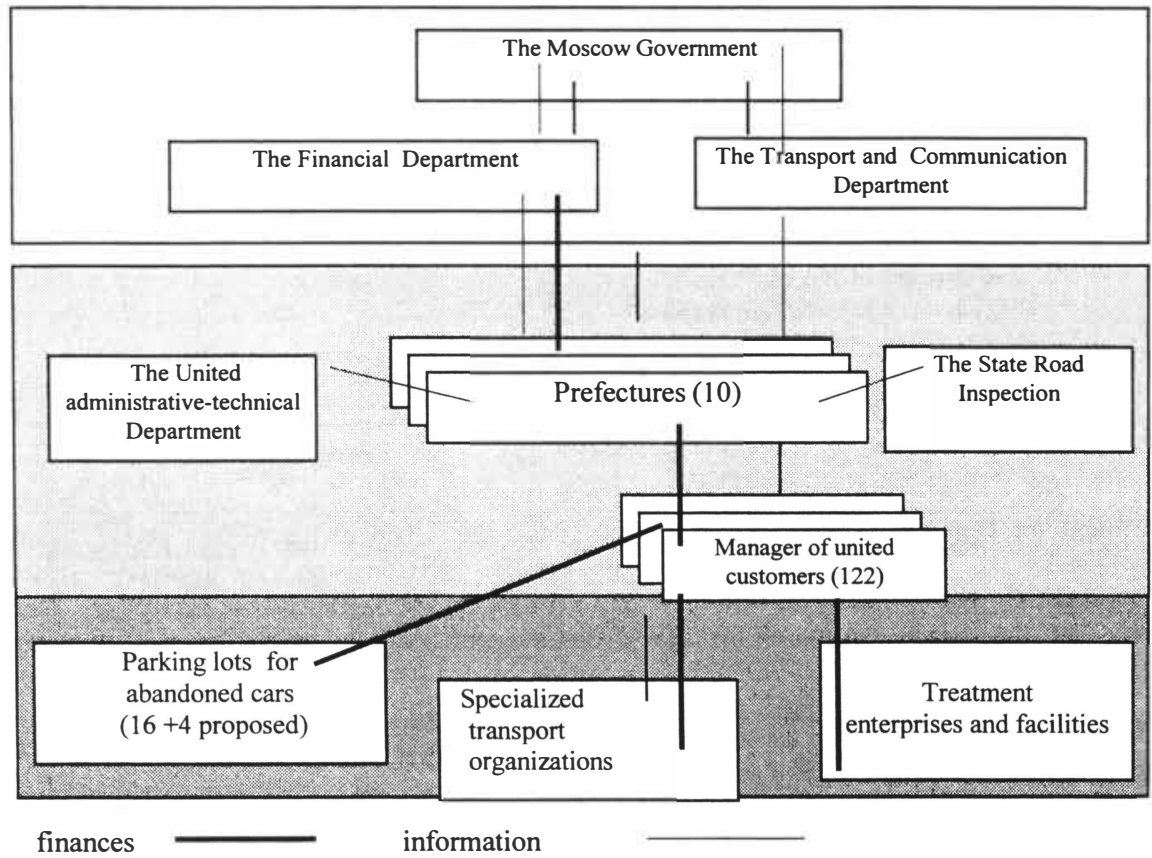

After evacuation of a vehicle to the parking lots the State Road Inspection carries out some work to identify it's owner. In the event of finding the owner the vehicle is issued after the payment of cost of transportation and keeping in accordance with approved tariffs. 


\section{Tariffs in worker execution in opening, evacuations, count, issue, storage and takedown of vehicles $(\$)$}

\begin{tabular}{|lcc|}
\hline Actions & Expenseses, $\mathbf{S}$ & $\%$ \\
Collection, keeping, evacuation & 90 & $60 \%$ \\
Dismantling & 25 & \\
Rubbish utilization & 3 & \\
Utilization of technical liquids & 2,8 & \\
(antifreeze, liquid of brake) & 5 & $40 \%$ \\
Tyres utilization & 0,2 & \\
Oil filter utilization & 3 & \\
Registrations of disposal certificate & $5+6$ & \\
Expenseses controlling companies + & & \\
development fund & Utilization of used battery, oil, metals & will be realized without attraction \\
of additional expenseses under self-financing conditions
\end{tabular}

The Article 225 of Civil Code of the Russia Federation provides 1- year period as a term required for confession a vehicle as an ownerless one. Upon expire of this period on the presentation of the Territorial tax inspection and the court decision the transport vehicle becomes the state property and is taken into account of the Territorial tax inspection. Only after that the further decision on the use of the transport vehicle ( utilization, realization and e.t.) can be taken.

However, neither Federal, nor Moscow legislation provides liability for natural persons for abandoning vehicles on the territory of city. In 1997 on the territory of Moscow there were about 16 thousand cars identified as abandoned.

Until 1995 all works were financed by the City budget. Expenseses constantly grow. In 1995, 1996, 1997 years the Moscow prefectures had to spend 300 th., 11670 th., 9239 th.rubles for collecting, keeping and utilization of abandoned cars.

Considering modern technical condition and normative period of amortization, number of vehicles unfit-to-use and requring salvage, will increase that will result in increase of budgetary expenseses. 
Budgetary expenses increase prognosis

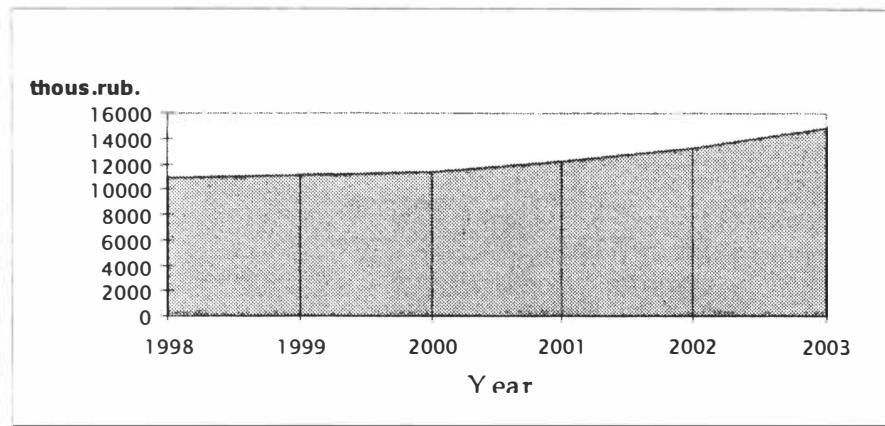

Taking into account the acting Federal legislation it is possible to make general conclusion: most rapt attention must be given to establishment of the system for collecting vehicles, belonging to natural owners. It is voluntary refusal of owners from their end-of-life cars in favour of states for further salvaging that must be encouraged since estranging abandoned cars in income of state is characterized by significant time loses and money expenditures for collection, keeping and legal registration of vehicles.

\section{Basic principles of development of waste management system. Experience of European}

Union. The efficient management system for any types of wastes must be based on the principle of sustainable development. The main rules of creation modern management system on the example of European Union experience are as follows.

Sustaintable and economically efficient functioning of the system can be achived only with implementation of the following conditions:

- to observe adopted hierarchy of priorities for management of waste flows. This hierarchy presumes:

-use of all possibilities for prevention of waste generation in source;

-re-use and recycling ;

-the waste- energy recovery;

-ecological correct landfilling.

- association of all stages in waste disposal chain (collection, re-use, conversion, incineration, lanfilling ) in an united ecological correct, organizationally and financially sustainable system;

- availability and development of a secondary materials market;

- elude of illegal waste dumping ;

- existance of strict system of control ;

- "polluter pays" principle

- complining waste management policy whith the united evironmental policy. 


\section{Scheme satisfying cardinal principles of sustainable development of waste management system (motor vehicle)}

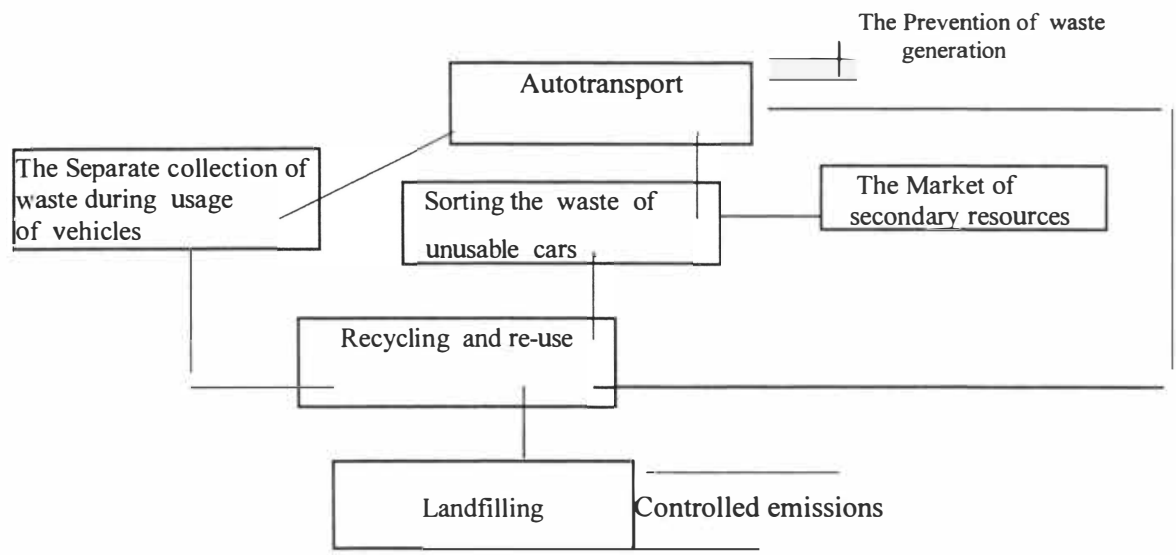

1. The first problem of the modern waste management system is to prevent waste generation in source:

- to use materials, which in consequence can be subjected to recycling;

- to develop and use technologies, allowing extend service life of spare parts of vehicle;

- to develop repair-working base.

2.The system must provide maximum use of the secondary resources.

In many countries of the world car producers are responsible for motor vehicle waste accomodation. This is the stimulus for producers to use the most suitable materials for recycling, as well as making the plants on takedown of end-of-life vehicles. The car production must relieve most their further stripping on completion of it's end-of -life period.

According to recommendations of EU Council by the year 2002, at the average $85 \%$ of materials used in car production must be subject to recycling, by the year $20 \notin 5$ this index must go up to $95 \%$. All cars released after 2002 must contain $90 \%$ of materials, suitable to reuse and recycling.

\section{EC recomendations on car recycling level}

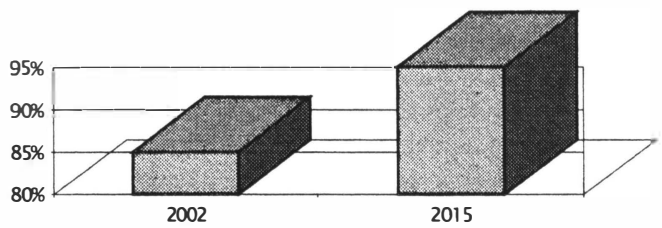

At present, at the average, $25 \%$ of each car weight is a subject for landfiling. It is forecasted that by the year 2000 this index must drop to $18 \%$. The strategic problem of 
development of a waste management system is reduction of waste generation up to $5 \%$ in weigth for each utilized car in EU countries.

\section{EC recomendations on car waste landfilling reduce}

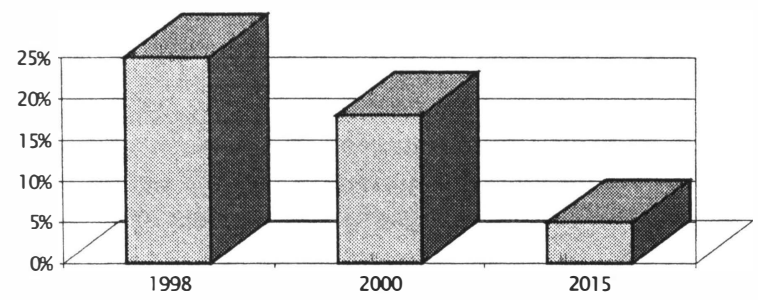

Main problem definition and it's analysis.

\section{Financial reasons:}

City budget is the only source of finance.

There is no any stimulation of motor vehicles owners to delivery of waste.

The Polluter Pays Principle is not introduced

The strict economical sanctions.

\section{Organization reasons:}

Absence of batteries and tyres collection system.

Absence of unfied registration on end-of-life vehicle collection and recovery volumes

Poor control for wastes flows

There is no Coordinator

There is no United data base on Moscow vehicle fleet .

Legal reasons:

There is no approved order of keeping transport vehicles on the territory of city (for consumers).

Absence of legal definition of wreaks

Existing legislative and normativ acts are oriented on collection of abandoned vehicles only.

Marketing reasons:

There is no market of secondary plastic products.

There is no stable market of secondary rubber and plastic products.

There are no processing complexes for scrap metals treatment.

All these reasons cause low efficiency of the car waste management system. This leads to ecological losses, decreasing of traffic safety, economical losses.

\section{The Concepcion of decision of the problem:}

\section{Financial aspect:}

- establishing Fund for accumulation of financial inputs, 
- introduction a mechanism of pawn cost of services on salvaging the cars (at the moment of registrations and car presentation for technical control).

- introduction a mechanism of penalty sanctions for keeping unfit to usages cars on territory of the city.

In perspective it is nessesery to introduse the principle of producer's responsobility for waste disposal according to European model (Sweden, the Netherlands, Germany).

\section{The Organizational aspect :}

- Determination of a Coordinator, which will be in charge for realization of united technical policies in the car waste management field;

-The creation of network of treatment enterprises in Moscow and Moscow region - making the production and development of existing capacity on treatment of all types of motor vehicles waste;

- creation to network on collection of used tyres, batteries, oil from private sector.

Normative-legal aspect :

- the development of an order for keeping of transport waste.

- the elimination of contradictions between federal and local legislations.

- development of ecological requirements relating to autotransport waste (use the experience of Sweden, Germany, the Netherlands)

\section{Marketing:}

- establishing market for secondary plastic products.

- establishing spare parts market for re-use

\section{The Priority actions for the next $\mathbf{1 - 2}$ years :}

1. To develop and approve legislative documents relating to transport waste;

2. The specify a Coordinator in the field of transport waste management;

3. To develop on united order for keeping of vehicles in Moscow;

4. To develop a territorial scheme of removing and processing of transport waste;

5. Introduction and start the pawn cost :

-development of financial model of pawn cost mechanism;

-development and realization of programs explanation the need and essences of mechanism for natural car owners;

-co-ordination of pawn cost mechanism with all town services,

-preparation of corresponding The Moscow Government decisions;

-shaping the unbudget fund sufficient for realization of the first project

6. Realization of the first project on collection and utilization the transport waste.

Conclusion. Currently, under orders of the Moscow Government the final work on formation of the concept of development of a transport waste management system will be carried out. Many interested organizations of the city take part in the creation of the concept and package of the legislative and normative documents of federal and local levels. These are : Moscow State Committee for Environmental Protection, Transport and Communication Department, Municipal Services Department, treatment enterprises, private firms and interested investors. Experience of foreign countries is throughly studied, especially experience of the Europe Union countries.

The practice of ratification of new bills on the federal level shows the time of the 
acceptance and the declaration of introduced the law can be pretty long. Therefore, with the aim to accelerate the decision on a sharp problem on practically uncontrollable grow of transport waste volumes in the near future parallel with development of the necessary legislative documents the reasonable investment program and it's mechanism should be finally generated. It is planned to announce an investment tender for realization of the program.

Moscow has to be a pioneer in the process of creation the first management transport waste system in Russia. The basic problem of the project realization at the present stage consists in the prompt development of local legislation, not contradicting to the existing federal one. At the same time. it is required to find the necessary investments for creation of an effiective system of the collecton and manufactures network on processing all kinds of generating wastes. 